\title{
Leishmania infection in cats and dogs housed together in an animal shelter reveals a higher parasite load in infected dogs despite a greater seroprevalence among cats
}

Gad Baneth $^{1^{*}} \mathbb{0}$, Yaarit Nachum-Biala ${ }^{1}$, Adam Zuberi ${ }^{1}$, Nirit Zipori-Barki ${ }^{2}$, Laor Orshan ${ }^{3}$, Gabriela Kleinerman $^{1}$, Ayelet Shmueli-Goldin², Michel Bellaiche², Monica Leszkowicz-Mazuz ${ }^{4}$, Harold Salant ${ }^{1}$ and Daniel Yasur-Landau ${ }^{4}$

\begin{abstract}
Background: An outbreak of leishmaniosis was studied in cats and dogs housed together with no separation in an animal shelter in Israel.

Methods: The study included recording of clinical signs, serology for Leishmania infection by ELISA, PCR of blood for Leishmania DNA by ITS1 HRM and kDNA PCR, parasite quantification, and trapping of sand flies around the shelter.

Results: Thirty-seven \% (22/60) of the dogs and 75\% (50/67) of the cats were seropositive to L. infantum with a significantly higher seropositivity rate in the cat population $\left(X^{2}=42.160, P<0.0001\right)$. Twenty-five percent $(15 / 60)$ of the dogs were positive for Leishmania by blood PCR, 12\% by the Leishmania ITS1 HRM PCR and 22\% by kDNA PCR. Of the cats, 16\% (11/67) were positive by kDNA PCR and none by ITS1 HRM PCR. All the PCR-positive animals were infected by L. infantum verified by DNA sequencing and there was no significant difference between the PCR-positivity in the dog and cat populations. Altogether, 43\% (26/60) of the dogs and 79\% (53/67) of the cats were positive by serology or PCR for L. infantum. The average Leishmania parasite load in the blood of PCR-positive dogs (42,967 parasites $/ \mathrm{ml})$ was significantly higher than in PCR-positive cats (1259 parasites $/ \mathrm{ml})\left(t_{(12)}=2.33, P=0.037\right)$. Dogs that were positive by the Leishmania ITS1 HRM PCR and KDNA PCR had significantly higher parasite loads than dogs positive only by the kDNA PCR $\left(t_{(11)}=-3.186580, P<0.009\right)$. No significant effect was found for FIV seropositivity on Leishmania infection in the cats $\left(X^{2}=0.506, P=0.777\right)$. A higher percentage of Leishmania-positive dogs showed clinical signs compatible with leishmaniosis compared to Leishmania-positive cats (100 vs 52.8\%, $\left.X^{2}=15.242, P<0.0001\right)$. Phlebotomus perfiliewi, a proven vector of $L$. infantum, comprised $92 \%$ of trapped sand flies.
\end{abstract}

Conclusions: Comparisons of populations of cats and dogs exposed to sand flies and L. infantum under the same conditions indicated that although a high rate of exposure was detected in cats as manifested by a significantly greater degree of seropositivity, dogs had significantly higher blood parasite loads, and were likely to be more infectious to sand flies than cats.

Keywords: High resolution melt analysis PCR, ITS1 PCR, Cat, Dog, Parasite load, Leishmania infantum

*Correspondence: gad.baneth@mail.huji.ac.il

${ }^{1}$ Koret School of Veterinary Medicine, The Hebrew University of Jerusalem, Rehovot, Israel

Full list of author information is available at the end of the article

c) The Author(s) 2020. This article is licensed under a Creative Commons Attribution 4.0 International License, which permits use, sharing, adaptation, distribution and reproduction in any medium or format, as long as you give appropriate credit to the original author(s) and the source, provide a link to the Creative Commons licence, and indicate if changes were made. The images or other third party material in this article are included in the article's Creative Commons licence, unless indicated otherwise in a credit line to the material. If material is not included in the article's Creative Commons licence and your intended use is not permitted by statutory regulation or exceeds the permitted use, you will need to obtain permission directly from the copyright holder. To view a copy of this licence, visit http://creativeco mmons.org/licenses/by/4.0/. The Creative Commons Public Domain Dedication waiver (http://creativecommons.org/publicdomain/ zero/1.0/) applies to the data made available in this article, unless otherwise stated in a credit line to the data. 


\section{Background}

Leishmaniosis caused by Leishmania infantum is a major zoonosis which affects humans and dogs in many regions of the world [1]. Cats also develop clinical disease due to L. infantum infection and may have dermal as well as visceral manifestations of this infection $[2,3]$. Although the number of feline cases of clinical disease with $L$. infantum seems lower than the number of canine cases in endemic areas, there is no sufficient comparative knowledge relating to the prevalence of leishmaniosis in domestic dogs and cats exposed to the same conditions of disease transmission.

Infection and disease with $L$. infantum may be related to several factors including biting preferences of sand flies, the size of inoculum during the sand fly bite, number of exposures to infectious bites during the sand fly season, the host's individual susceptibility, the nature of the immune response mounted to infection, co-infection with other pathogens and possible host immune suppression.

This study investigated an outbreak of leishmaniosis in cats and dogs housed together with no separation in an animal shelter in Israel. It provided a unique opportunity to evaluate infection in dog and cat populations exposed to the same environmental and physical conditions.

\section{Methods}

\section{Dogs and cats included in the study}

Totals of 67 cats and 60 dogs housed together in a private animal shelter in northern Israel were included in the study. The animals had free movement within the compound and there was no separation between cats and dogs. The shelter was eventually closed by the Israeli Veterinary Services due to poor sanitary and nutritional conditions and the animals were moved in June 2018 to temporary accommodation where they all had a physical examination and collection of blood samples to test for leishmaniosis due to the presence of suspicious skin lesions in some of the dogs and cats.

\section{Collection of blood}

Blood was collected by venipuncture of the jugular or cephalic veins of the dogs and cats who were included in the study on June 25th 2018. The blood was collected into EDTA and clot tubes for PCR and Leishmania serology, respectively. Physical examination was performed by experienced veterinarians and abnormalities were recorded for each animal.

\section{Serology}

Serum anti-leishmanial antibodies were determined by ELISA, using crude leishmanial antigen, essentially as previously described [4]. All sera were diluted to 1:100 and incubated with leishmanial antigen (L. infantum strain MCAN/IL/2010/TR1) coated plates for one hr at $37{ }^{\circ} \mathrm{C}$. The plates were then washed with $0.1 \%$ Tween 20 in $50 \mathrm{mM}$ phosphate-buffered saline (PBS) at pH 7.2. Cat sera were then incubated with rabbit anti cat IgG antigen conjugated to horseradish peroxidase $(1: 10,000$ dilution; OriGene Technologies, Inc. Rockville, MD, USA) whereas dog sera were incubated with Protein A conjugated to horseradish peroxidase (1:10,000 dilution; Zymed Laboratories, Inc., San Francisco, CA, USA) for 1 $\mathrm{hr}$ at $37^{\circ} \mathrm{C}$. Excess conjugate was removed by extensive washing in PBS-Tween and the plates were developed by addition of the substrate 2,29-azino-di-3-ethylbenzthiazoline sulfonate (ABTS) (Sigma-Aldrich-Merck, Jerusalem, Israel). Each plate was read when the absorbance (lambda $=405 \mathrm{~nm}$ ) of the positive reference serum reached an optical density (OD) value between 1.1-1.2 for cat samples and 1.2-1.4 for dog samples. A titration of positive and negative reference cat or dog sera were included on each plate to monitor inter-assay variation. A serological cut-off of 0.4 OD for cats and for dogs was calculated based on four standard deviations above the mean OD values of readings from eight control sera of PCR-negative cats and dogs, respectively, from nonendemic areas for leishmaniosis. Borderline positive levels were considered antibody levels that were in the range between the three and four standard deviations which were $0.2-0.4$ OD for dogs and $0.3-0.4$ for cats.

Serology of the cat sera for antibodies against the feline immunodeficiency virus (FIV) was performed using the Megacor FASTest (Megacor Diagnostik, Hoerbranz, Austria).

\section{DNA extraction, PCR for Leishmania and DNA sequencing}

DNA was extracted from $200 \mu \mathrm{l}$ of EDTA-anticoagulated blood samples from the dogs using the Illustra blood genomicPrep Mini Spin Kit (GE Health care, Buckinghamshire, UK), following the manufacturer's instructions. Leishmania detection was performed by real-time PCR using primers JW11/JW12 targeting a 120 bp sequence of the Leishmania short fragment from the kinetoplast minicircle (kDNA) [5]. Additional detection and identification was carried out by PCR using primers ITS-219F and ITS-219R to amplify a 265-bp fragment of the Leishmania ribosomal operon internal transcribed spacer 1 (ITS1) region and then evaluated by high resolution melt (HRM) analysis (Leishmnia ITS1 HRM PCR) [6]. PCR was performed using the StepOnePlus real-time PCR thermal cycler (Applied Biosystems, Foster City, CA, USA) as previously described [7]. DNA extracted from parasite promastigote culture of $L$. infantum was used as positive control for PCR and DNA 
from colony-bred dogs negative by PCR for vector-borne pathogens including L. infantum was used as a negative control. A non-template control (NTC) with the same reagents described above but without DNA was added to each PCR to rule out contamination.

Positive DNA amplicons were purified (EXO-Sap, New England Biolabs Inc., Ipswich, MA, USA) and sequenced in the Center for Genomic Analyses at the Hebrew University (Jerusalem, Israel) using the BigDye Terminator cycle from Applied Biosystems ABI3700 DNA Analyzer. The ABI Data Collection and Sequence Analysis software (ABI, Carlsbad, CA, USA) was used for analysis. DNA sequences were compared to other sequences deposited in GenBank using the BLASTn website hosted by NCBI, National Institutes of Health, USA (http://www.ncbi.nlm. nih.gov).

\section{Quantitation of Leishmania in blood}

Samples that were positive by PCR were further analyzed to evaluate the blood parasite load. Quantitative PCR of leishmanial DNA from the positive samples was carried out by amplification of a $120 \mathrm{bp}$ of the kDNA using primers JW11/JW12 [5]. To generate a standard curve, 10-fold dilutions of DNA extracted from parasite promastigote cultures of L. infantum at concentrations of $10^{1}-10^{8}$ promastigotes were used. Real-time PCR was carried as mentioned above. The number of parasites in each sample was calculated against the standard curve using the StepOne software version 2.2.2 (Thermo Fisher Scientific, Waltham, MA USA).

\section{Sand flies}

Sand flies were collected from five locations around the fence of the animal shelter on July 30th 2018. Modified CDC traps operated without light powered by two $1.2 \mathrm{~V}$ AA rechargeable batteries and baited with one kg of dry ice were placed from sunset to sunrise in a vertical position. The openings were parallel to the ground and $\sim 10$ $\mathrm{cm}$ above it and the fan was adjusted to create updraft airflow with the collection boxes hanging above the body of the trap. The catch was chilled and kept at $-20^{\circ} \mathrm{C}$ until sorting. All sand fly males were identified to the species level by the morphology of the genitalia using the keys of Abonnec \& Lewis $[8,9]$. The females were not identified to the species level and pooled in groups of 20 specimens for molecular detection of Leishmania DNA. All samples were stored at $-20{ }^{\circ} \mathrm{C}$ until testing. DNA was extracted from the homogenized pooled females using the QIAsymphony DNA Mini Kit and the QIAsymphony SP machine (Qiagen N.V. Venio, The Netherlands) and PCR was performed using the Leishmania ITS1 HRM PCR [6]. PCR was performed in a total volume of $20 \mu \mathrm{l}$, containing $10 \mu \mathrm{l}$ of AccuMeltHRM SuperMix (Quanta
Bioscience, Gaithersburg, USA), $0.5 \mu \mathrm{M}$ of each primer, $5 \%$ DMSO (w/v) and $3 \mu \mathrm{l}$ DNA, using the Roche LightCycler $96^{\circledR}$ (Roche, Mannheim, Germany). The cycling parameters were $95^{\circ} \mathrm{C}$ for $5 \mathrm{~min} ; 45$ cycles of $95^{\circ} \mathrm{C}$ for 10 s; $60{ }^{\circ} \mathrm{C}$ for $45 \mathrm{~s}, 95^{\circ} \mathrm{C}$ for $60 \mathrm{~s}, 40^{\circ} \mathrm{C}$ for $60 \mathrm{~s}, 65^{\circ} \mathrm{C}$ for $1 \mathrm{~s}$ $97^{\circ} \mathrm{C}$ for $1 \mathrm{~s}, 37^{\circ} \mathrm{C}$ for $30 \mathrm{~s}$.

\section{Statistical analysis}

Student's t-test and the Chi-square test were used for ordinal (positive, negative and borderline) and nominal (parasites load) variables, respectively. The continuity correction was used when $2 \times 2$ tables were used. Pearson's correlation coefficient was used to test correlation between variables. Statistical analysis was performed using the statistics software SPSS(R) 25.0 software (IBM, Armonk, New York, USA). Statistical significance was defined as $P<0.05$.

\section{Results}

\section{Serology, PCR and parasite loads}

Thirty-seven percent $(22 / 60)$ of the dogs were seropositive to $L$. infantum antigen by ELISA whereas $75 \%$ (50/67) of the cats were seropositive (Table 1). Accordingly, seroreactivity with $L$. infantum in the cat population at the shelter was significantly higher than in the dog population $\left(\chi^{2}=42.160, d f=1, n=127, P<0.0001\right)$.

Twenty-five percent $(15 / 60)$ of the dogs were positive for Leishmania by blood PCR. Seven (12\%) were positive by the Leishmania ITS1 HRM PCR and 13 (22\%) by kDNA PCR, with five positive by both PCRs, eight only by kDNA and two only by ITS1 PCR. Of the cats, $16 \%(11 / 67)$ were positive by kDNA PCR and none were positive by ITS1 PCR. All the PCR-positive animals were verified as positive to $L$. infantum by DNA sequencing and BLAST analysis (Additional file 1: Table S1). There was no significant difference between the PCR-positivity

Table 1 Results of ELISA serology and PCR in dogs and cats from the animal shelter

\begin{tabular}{llll}
\hline Diagnostic assay & Animal status & $\begin{array}{l}\text { Dogs } \\
n(\%)\end{array}$ & $\begin{array}{l}\text { Cats } \\
n(\%)\end{array}$ \\
\hline Serology & Positive & $22(36.6)$ & $50(74.6)$ \\
& Borderline & $4(6.6)$ & $14(20.9)$ \\
& Negative & $34(56.6)$ & $3(4.5)$ \\
& Total & 60 & 67 \\
PCR (Leishmania ITS1 HRM and & Positive & $15(25.0)$ & $11(16.4)$ \\
kDNA) & Negative & $45(75.0)$ & $56(83.6)$ \\
& Total & 60 & 67 \\
Positive by serology and PCR & & $11(18.3)$ & $8(11.9)$ \\
Positive by serology and/or PCR & & $26(43.3)$ & $53(79.1)$ \\
\hline
\end{tabular}


prevalence of the dog and cat populations $\left(\chi^{2}=1.445, d f\right.$ $=1, n=127, P=0.229$ ).

Altogether, 43\% (26/60) of the dogs and 79\% (53/67) of the cats were positive either by serology or PCR for $L$. infantum and the prevalence of positivity by at least one of these diagnostic methods in the cats was significantly higher than in the dog population $\left(\chi^{2}=39.221, d f=1\right.$, $n=127, P<0.0001)$. Of the PCR-positive dogs, $11 / 15$ were seropositive (OD $>0.4$ ), two were borderline positive (OD 0.2-0.4) and two were seronegative (OD $<0.2)$ (Table 1). All the PCR-positive cats were either seropositive (OD $>0.4 ; n=8$ ) or borderline-positive (OD 0.3-0.4; $n=3)$.

The average Leishmania parasite load in the blood of PCR-positive dogs (42,967 parasites/ml; range: 305$219,975)$ was significantly higher than the parasite load in PCR-positive cats (1259 parasites/ml; range: 470-1975) $\left(t_{(12)}=2.33, P=0.037\right)$ indicating that PCR-positive infected dogs harbored a higher parasite load in their blood than PCR-positive infected cats exposed to $L$. infantum infection under the same environmental conditions. Furthermore, while there was a fair correlation $\left(r^{2}\right.$ $=0.7, P=0.007$ ) between the antibody levels expressed as OD in dogs and their blood parasite load, there was no such positive correlation found between antibody levels and parasite loads for the PCR-positive cats $\left(r^{2}=\right.$ $-0.125, P=0.73)$. Dogs that were positive by the Leishmania ITS1 HRM PCR and kDNA PCR $(n=5)$ had significantly higher parasite loads than dogs that were positive only by the kDNA PCR $(n=8)$ (averages 97,157 parasite $/ \mathrm{ml}$ and 9099 parasite $/ \mathrm{ml}$, respectively $\left(\mathrm{t}_{(11)}=\right.$ $-3.186580, P=0.009$ ).

FIV serology was positive in $7 \%(5 / 67)$ of the cats. Of these cats, two were seropositive for L. infantum, one was borderline seropositive, and two were seropositive and PCR-positive. No significant effect was found for FIV seropositivity on Leishmania infection in the evaluated cats $\left(\chi^{2}=0.506, d f=1, n=67, P=0.777\right)$.

All dogs and cats were screened for clinical signs on physical examination. Clinical signs potentially related to leishmaniosis included skin lesions (Figs. 1, 2, 3, 4), lymphadenomegaly, splenomegaly, ocular lesions, severe weight loss and emaciation. These clinical signs may have also been associated with some other medical conditions which were not determined due to the limited resources devoted for the medical examination of the animals. Overall, $88 \%(53 / 60)$ of the dogs had clinical signs that could be associated with leishmaniosis, nevertheless, only $49 \%$ (26/53) were positive for Leishmania infection by serology or PCR. Fifty-five percent (37/67) of the cats had clinical signs compatible with leishmaniosis, of which $76 \%$ (28/37) were positive by serology or PCR for

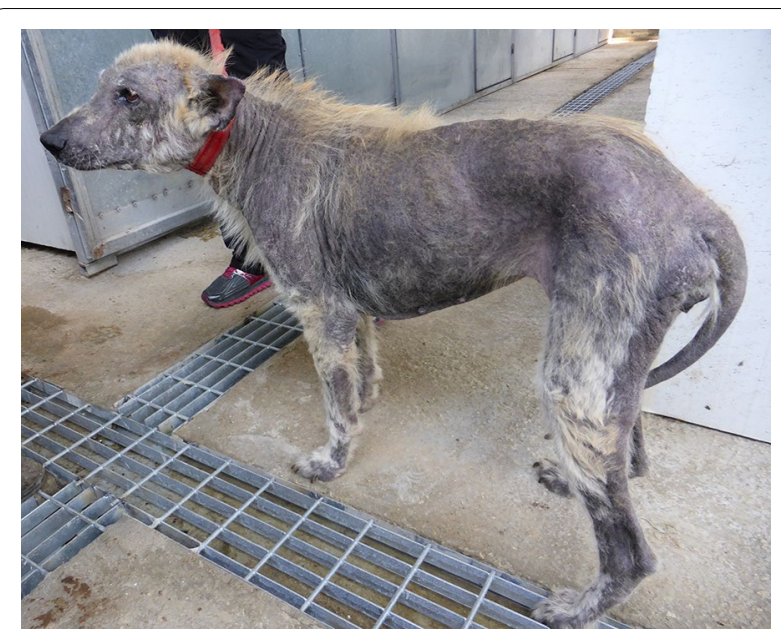

Fig. 1 A dog from the animal shelter that was positive for $L$. infantum by serology and PCR. The dog has overt alopecia and hyperkeratosis with purulent keratoconjunctivitis typical of canine leishmaniosis

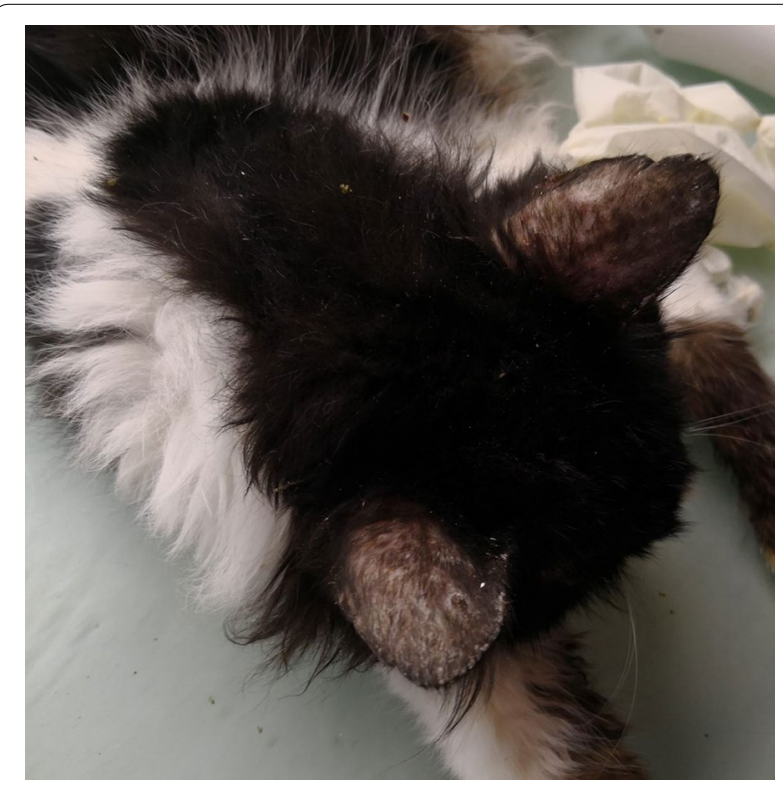

Fig. 2 Aural alopecia and in a cat from the animal shelter that was seropositive with a high antibody level for $L$. infantum

L. infantum. All of the dogs that were positive by either serology or PCR had clinical signs compatible with leishmaniosis, but only $53 \%(28 / 53)$ of the cats which were positive by at least one of these diagnostic techniques had clinical signs of disease. Overall, a higher percentage of Leishmania-positive dogs showed clinical signs that could be related to leishmaniosis compared to Leishmania-positive cats (100 vs 53\%, $\chi^{2}=15.242, d f=1, n=$ 127, $P<0.0001)$. 


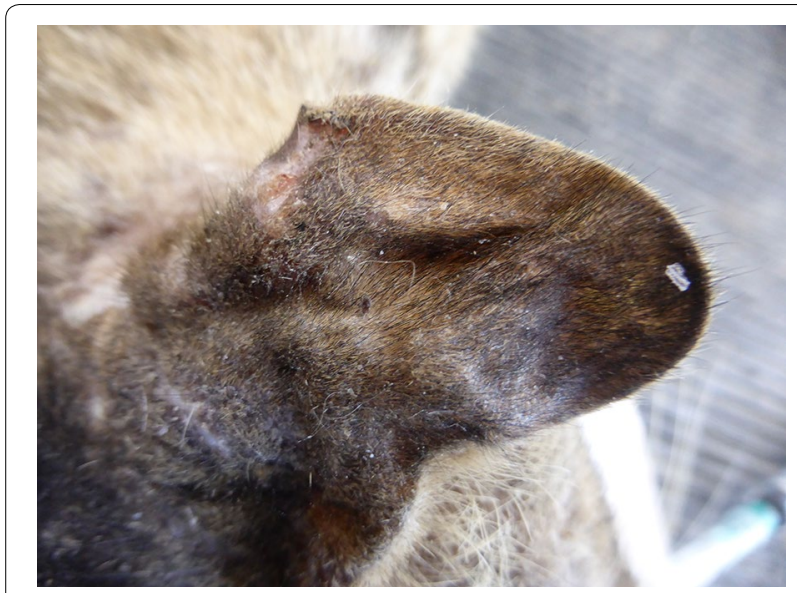

Fig. 3 Ulcerative skin lesions, partial alopecia and scales on the ear of a cat from the animal shelter that was seropositive with a high antibody level for $L$. infantum

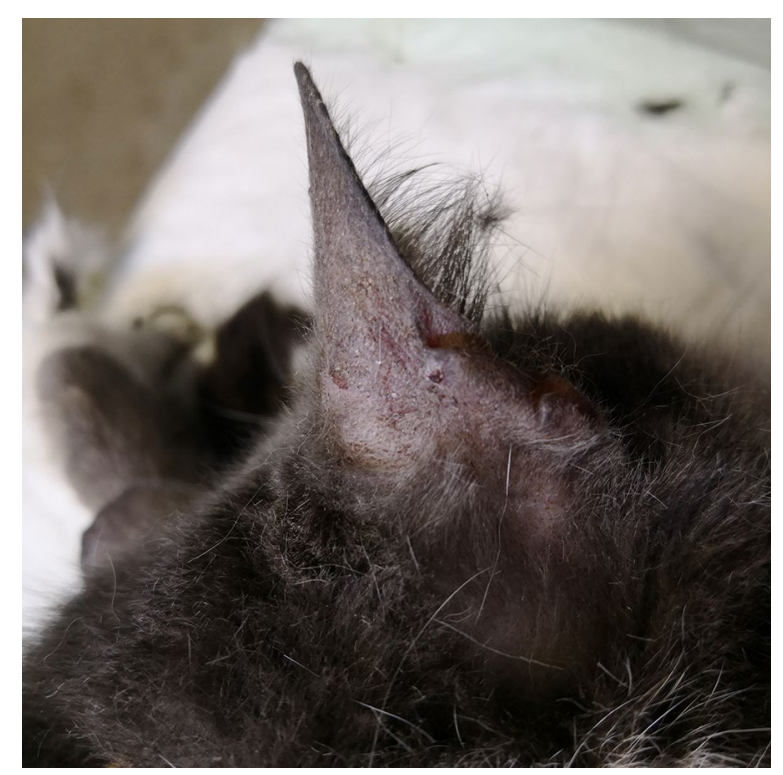

Fig. 4 Complete alopecia and skin ulceration in the ear of a $L$. infantum-seropositive cat with a high antibody level

\section{Sand flies}

A total of 633 Phlebotomus spp. sand flies were collected by the five traps at the shelter approximately 8 weeks after the animals had been removed from it (Table 2). Phlebotomus perfiliewi, a proven vector of L. infantum, comprised $92 \%$ of trapped sand flies, while P. tobbi and $P$. papatasi accounted for $3 \%$ and $5 \%$ of the remaining sand flies, respectively. Leishmania DNA was not detected in any of the 19 female sand fly pools tested.

\section{Discussion}

Most of the epidemiological surveys on canine and feline leishmaniosis have studied only dogs or cats, and very few have studied infection in both animal species living in the same area $[10,11]$. The present study included dogs and cats that shared a small restricted compound where they mixed freely in the presence of abundant numbers of sand fly vectors, as inferred by the entomological survey performed after the shelter was evacuated from animals. It is reasonable to hypothesize that the dogs and cats living together in the same compound had similar exposure to infectious sand flies. Therefore, this study provided a unique opportunity to compare infection of dogs and cats with L. infantum which was different from previous studies performed in larger and more diverse environments such as metropolitan Lisbon and the Aeolian islands in Italy $[10,11]$.

Although serology and blood PCR tend to underestimate $L$. infantum infection rates in canine populations [12], and possibly also in feline populations, the present study detected high infection rates as indicated by serology and/or PCR in $43 \%$ of the dogs and $79 \%$ of the cats. These rates are higher than $41.8 \%$ and $25.8 \%$ found by serology, blood and conjunctival PCR for dogs and cats, respectively, in the small Aeolian islands of Lipari and Vulcano [11]. When evaluating only kDNA PCR of blood, $22 \%$ of the dogs and $16 \%$ of the cats in our study were positive while only $12.2 \%$ of the dogs and $2.1 \%$ of the cats in the Aeolian islands study were positive [11]. In contrast, in a study from the Lisbon metropolitan area in Portugal, $34.9 \%$ of the dogs and $20.3 \%$ of the cats were kDNA PCR-positive [10].

Surprisingly, seroreactivity with $L$. infantum in the feline population of the shelter (75\%) was significantly more prevalent that in the canine population (37\%). This is opposite from the situation in the Aeolian islands study where $25.7 \%$ of the cats and $34.6 \%$ of the dogs surveyed were positive by the indirect immunofluorescence test (IFAT) [11]. The ratio between cat and dog seroreactivity was even lower in the Lisbon metropolitan area study where only one cat of 76 was seropositive by IFAT whereas $20.4 \%$ of the dogs were seropositive, and the authors of the study suggested that the serological test which they used may not have been sufficiently sensitive for detection of anti-leishmanial antibodies in cats [10]. The reason for the high seroprevalence rate in the shelter cats from Israel may have been due to the extensive close contact of these cats with infected dogs harboring a high parasite load in the presence of abundant sand fly vectors in a small compound. It may have also been related to their close association with many other infected cats under these conditions. 
Table 2 Trapping of sand flies in the shelter area and identification of sand fly species

\begin{tabular}{llllllll}
\hline Trap No. & $\begin{array}{l}\text { No. of } \\
\text { specimens }\end{array}$ & No. of females (\%) & No. of males (\%) & $\begin{array}{l}\text { No. of sand fly pools } \\
\text { tested for Leishmania } \\
\text { DNA }\end{array}$ & $\begin{array}{l}\text { No. of male } \\
\text { Phlebotomus } \\
\text { perfiliewi (\%) }\end{array}$ & $\begin{array}{l}\text { No. of male } \\
\text { Phlebotomus } \\
\text { papatasi (\%) }\end{array}$ & $\begin{array}{l}\text { No of male } \\
\text { Phlebotomus } \\
\text { tobbi (\%) }\end{array}$ \\
\hline 1 & 289 & $235(81)$ & $54(19)$ & 8 & $52(96)$ & 0 & $2(4)$ \\
2 & 90 & $45(50)$ & $45(50)$ & 3 & $45(100)$ & 0 & 0 \\
3 & 68 & $32(47)$ & $36(53)$ & 2 & $36(100)$ & 0 & 0 \\
4 & 118 & $64(54)$ & $54(46)$ & 3 & $46(85)$ & 0 & $8(15)$ \\
5 & 68 & $53(78)$ & $15(22)$ & 3 & $8(53)$ & $7(43)$ & 0 \\
Total & 633 & $429(68)$ & $204(32)$ & 19 & $187(92)$ & $7(3)$ & $10(5)$ \\
\hline
\end{tabular}

a Percent of males

The finding that L. infantum PCR-positive dogs had significantly higher parasite loads compared to PCR-positive cats exposed to infection under the same conditions agrees with the possibility that dogs may be better reservoirs and spreaders of $L$. infantum compared to cats. The parasite load in the blood and skin of dogs naturally infected with L. infantum has been found to be correlated with their capacity to infect sand fly vectors [13]. Although cats have been shown experimentally to infect sand flies by xenodiagnosis $[14,15]$, the relationship between their parasite loads and infectiousness to sand flies has not been studied, and it is unknown how successful they are as spreaders of L. infantum under natural conditions.

The fact that the ITS1 HRM PCR detected infection in dogs with significantly higher parasite loads than the dogs detected only by the kDNA PCR can be explained by the lower copy number of the ITS1 locus in comparison to the targeted copy number of kDNA minicircle sequence. There are about 10,000 copies of the kDNA and only 40-200 copies of the ITS1 region of the rRNA gene in each individual Leishmania parasite [16]. This also explains why cats in this study were negative by ITS1 HRM PCR despite being positive by kDNA, as their average blood parasite load was considerably lower than that of positive dogs. Hence, kDNA was shown to be preferred over the ITS1 as a Leishmania PCR target for blood PCR of cats.

The finding of a fair correlation between the antibody levels and parasite load in dogs but not in cats may also be associated with the relatively low parasite load of infected cats and perhaps the different biological behavior of L. infantum in exposed cats, where positive serology was highly prevalent, but the magnitude of blood parasitemia appeared to be lower than in dogs exposed to the same conditions.

FIV serology was positive in $7 \%$ of the cats and no statistically significant association was found between FIV and L. infantum infections. Some other studies on large numbers of cats in Italy and Brazil have found an association between feline leishmaniosis and FIV [17, 18] whereas studies from Spain and Cyprus failed to find such an association $[19,20]$. It is likely that an association between FIV and L. infantum infection was not found in the present study due to the small number of FIV-positive cats detected in the shelter and the overall limited feline population size evaluated.

Evaluation of infection with other potential co-infecting agents such as Ehrlichia canis, Anaplasma platys, and Babesia spp. in dogs, and the feline leukemia virus (FeLV), Bartonella spp., hemotrophic mycoplasmas and Toxoplasma gondii infections in cats was not included in the study due to lack of financial support for the performance of these assays on samples from all the animals. Although FIV has been shown to be a common infection of shelter cats in Israel with $12 \%$ seroprevalence in a previous study, FeLV infection was found only in $4 \%$ of the cats in that study and seems to be an uncommon infection in Israeli cats [21].

The clinical evaluation of the cats and dogs was challenging because the animals were kept in poor sanitary and nutritional conditions at the shelter, and also due to the lack of further testing by hematology, serum biochemistry, and urinalysis which could provide important information on the clinical condition of infected animals $[1,2]$. Furthermore, except for FIV serology, no other tests for additional infectious agents were performed. Most of the dogs (88\%) and cats (55\%) in the shelter had physical examination findings that were compatible with leishmaniosis and eventually after testing for the infection using specific tests, it was shown that indeed a significantly higher percentage of the dogs that were Leishmania-positive by serology or PCR had clinical signs of the disease when compared to their feline counterparts. This is reasonable when relating to the dog as the main host of the disease which often develops clinical disease after exposure to infection while the cat appears to be less frequently affected clinically by L. infantum 
with a much smaller number of clinical cases documented in the veterinary literature $[2,3]$.

To our knowledge, this is the first report of feline leishmaniosis in Israel. Israel is endemic for three species of Leishmania, L. tropica and L. major, which cause cutaneous leishmaniasis in humans, and L. infantum which causes visceral leishmaniasis [22]. Although L. major and L. tropica have been shown to cause disease in rare cases of dogs in Israel [23-25], and both of these species have been reported to infect cats apparently asymptomatically in Turkey [26, 27], infection in the animal shelter was shown to be caused by L. infantum by DNA sequencing of the PCR products.

Phlebotomus perfiliewi was the dominant species in the sand fly catch. This species is considered a proven vector of L. infantum in Algeria and Italy and putative vector in other regions around the Mediterranean Sea including Israel [28]. Its presence in relative high abundance in all the traps placed around the shelter indicates a high likelihood of local transmission of L. infantum. While the second most abundant sand fly species found in the shelter area, $P$. papatasi is a vector of $L$. major in Israel, but not of $L$. infantum [22], the third species $P$. tobbi found only in small numbers is a vector of $L$. infantum [29]. The lack of positive detection of $L$. infantum in the females is reasonable in a collection conducted eight weeks after the removal of the infected animals from the area, and low infection rates of L. infantum in sand flies in general [30, 31].

\section{Conclusions}

Comparison of cats and dogs exposed similarly to sand fly vectors and $L$. infantum infection in a small compound revealed a higher degree of seropositivity in the cats with similar PCR-positivity rates in both species, however, a significantly higher parasite load in the dogs, suggesting that dogs could be more infectious to sand flies and efficient in spreading the infection.

\section{Supplementary information}

Supplementary information accompanies this paper at https://doi. org/10.1186/s13071-020-3989-3.

Additional file 1: Table S1. Results of BLAST for Leishmania ITS1 and kDNA sequences amplified from the blood of dogs and cats included in the study by PCR. The GenBank accession number of first match by BLAST, species name, identity $\%$, coverage $\%$, and number of base pairs compared excluding the primer sequences are included for each positive animal.

\section{Abbreviations}

PCR: polymerase chain reaction; EDTA: ethylenediaminetetraacetic acid; NTC: non-template control.

\section{Acknowledgements}

Publication of this paper has been sponsored by Bayer Animal Health in the framework of the 15th CVBD World Forum Symposium.

\section{Authors' contributions}

GB and YNB designed the study. GB, AZ, NZ, GK, ASG, HS, MLM, MB, DYL and YNB collected the dog and cat samples. YNB and AZ performed the PCR. LO collected the sand flies and analyzed their species. YNB and GB performed serology and analyzed the quantitative and molecular data. GB, YNB, NZ, HS, MB, MLM NZ, ASG and DYL conceived the manuscript. All authors read and approved the final manuscript.

\section{Funding}

The study was funded by the corresponding author's internal resources.

\section{Availability of data and materials}

All data generated or analyzed during this study are included in this published article.

\section{Ethics approval and consent to participate}

Not applicable. Testing of the animals for leishmaniosis was performed due to clinical suspicion of this disease as commissioned by the Israeli Veterinary Services.

\section{Consent for publication}

Not applicable.

\section{Competing interests}

The authors declare that they have no competing interests.

\section{Author details \\ ${ }^{1}$ Koret School of Veterinary Medicine, The Hebrew University of Jerusalem, Rehovot, Israel. ${ }^{2}$ The Israeli Veterinary Services and Animal Health, Israeli Ministry of Agriculture, Bet Dagan, Israel. ${ }^{3}$ Central Laboratories Jerusalem, The Israeli Ministry of Health, Jerusalem, Israel. ${ }^{4}$ Division of Parasitology, Kimron Veterinary Institute, Bet Dagan, Israel.}

Received: 25 January 2020 Accepted: 24 February 2020 Published online: 20 March 2020

\section{References}

1. Solano-Gallego L, Miró G, Koutinas A, Cardoso L, Pennisi MG, Ferrer L, Bourdeau P, et al. LeishVet guidelines for the practical management of canine leishmaniosis. Parasites Vectors. 2011:4:86.

2. Pennisi MG, Cardoso L, Baneth G, Bourdeau P, Koutinas A, Miró G, et al. LeishVet update and recommendations on feline leishmaniosis. Parasites Vectors. 2015;8:302.

3. Pennisi MG, Persichetti MF. Feline leishmaniosis: is the cat a small dog? Vet Parasitol. 2018;251:131-7.

4. Baneth G, Dank G, Keren-Kornblatt E, Sekeles E, Adini I, Eisenberger CL, et al. Emergence of visceral leishmaniasis in central Israel. Am J Trop Med Hyg. 1998;59:722-5.

5. Nicolas L, Milon G, Prina E. Rapid differentiation of Old World Leishmania species by LightCycler polymerase chain reaction and melting curve analysis. J Microbiol Methods. 2002;51:295-9.

6. Talmi-Frank D, Nasereddin A, Schnur LF, Schönian G, Töz SO, Jaffe CL, et al. Detection and identification of old world Leishmania by high resolution melt analysis. PLoS NegI Trop Dis. 2010;4:e581.

7. Yasur-Landau D, Jaffe CL, David L, Baneth G. Allopurinol resistance in Leishmania infantum from dogs with disease relapse. PLoS Negl Trop Dis. 2016;10:e0004341.

8. Abonnec E. Les Phlébotomes de la région éthiopienne (Diptera, Psychodidae). Mém Off Rech Sci Tech Outre-mer. 1972;55:1-289.

9. Lewis DJ. A taxonomic review of the genus Phlebotomus (Diptera: Psychodidae). Bull Br Mus Nat Hist. 1982;45:121-209.

10. Maia C, Gomes J, Cristóvão J, Nunes M, Martins A, Rebêlo E, et al. Feline Leishmania infection in a canine leishmaniasis endemic region, Portugal. Vet Parasitol. 2010;174:336-40. 
11. Otranto D, Napoli E, Latrofa MS, Annoscia G, Tarallo VD, Greco G, Lorusso $E$, et al. Feline and canine leishmaniosis and other vector-borne diseases in the Aeolian Islands: pathogen and vector circulation in a confined environment. Vet Parasitol. 2017;236:144-51.

12. Baneth G, Koutinas AF, Solano-Gallego L, Bourdeau P, Ferrer L. Canine leishmaniosis — new concepts and insights on an expanding zoonosis: part one. Trends Parasitol. 2008;24:324-30.

13. Borja LS, Sousa OMF, Solcà MDS, Bastos LA, Bordoni M, Magalhães JT, et al. Parasite load in the blood and skin of dogs naturally infected by Leishmania infantum is correlated with their capacity to infect sand fly vectors. Vet Parasitol. 2016;229:110-7.

14. Maroli M, Pennisi MG, Di Muccio T, Khoury C, Gradoni L, Gramiccia M. Infection of sandflies by a cat naturally infected with Leishmania infantum. Vet Parasitol. 2007;145:357-60.

15. da Silva SM, Rabelo PF, Gontijo Nde F, Ribeiro RR, Melo MN, Ribeiro VM, et al. First report of infection of Lutzomyia longipalpis by Leishmania (Leishmania) infantum from a naturally infected cat of Brazil. Vet Parasitol. 2010;174:150-4.

16. Bensoussan E, Nasereddin A, Jonas F, Schnur LF, Jaffe CL. Comparison of PCR assays for diagnosis of cutaneous leishmaniasis. J Clin Microbiol. 2006;44:1435-9.

17. Sobrinho LS, Rossi CN, Vides JP, Braga ET, Gomes AA, de Lima VM, et al. Coinfection of Leishmania chagasi with Toxoplasma gondii, Feline Immunodeficiency Virus (FIV) and Feline Leukemia Virus (FeLV) in cats from an endemic area of zoonotic visceral leishmaniasis. Vet Parasitol. 2012;187:302-6.

18. Iatta R, Furlanello T, Colella V, Tarallo VD, Latrofa MS, Brianti E, Trerotoli P, et al. A nationwide survey of Leishmania infantum infection in cats and associated risk factors in Italy. PLoS Negl Trop Dis. 2019;13:e0007594

19. Solano-Gallego L, Rodríguez-Cortés A, Iniesta L, Quintana J, Pastor J, Espadam Y, et al. Cross-sectional serosurvey of feline leishmaniasis in ecoregions around the Northwestern Mediterranean. Am J Trop Med Hyg. 2007;76:676-80

20. Attipa C, Papasouliotis K, Solano-Gallego L, Baneth G, Nachum-Biala Y,

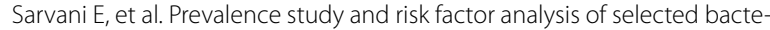
rial, protozoal and viral, including vector-borne, pathogens in cats from Cyprus. Parasites Vectors. 2017;10:130.

21. Baneth G, Kass PH, Steinfeld D, Besser M. A seroepidemiological study of feline coronavirus, feline immunodeficiency virus and feline leukemia virus among cats in Israel. Isr J Vet Med. 1999;54:39-42.
22. Jaffe $C L$, Baneth $G$, Abdeen $Z A$, Schlein $Y$, Warburg A. Leishmaniasis in Israel and the Palestinian Authority. Trends Parasitol. 2004;20:328-32.

23. Baneth G, Zivotofsky D, Nachum-Biala Y, Yasur-Landau D, Botero AM. Mucocutaneous Leishmania tropica infection in a dog from a human cutaneous leishmaniasis focus. Parasites Vectors. 2014;7:118.

24. Baneth G, Nachum-Biala Y, Shabat Simon M, Brenner O, Gaier S, Rojas A, Yasur-Landau D. Leishmania major infection in a dog with cutaneous manifestations. Parasites Vectors. 2016;9:246.

25. Baneth G, Yasur-Landau D, Gilad M, Nachum-Biala Y. Canine leishmaniosis caused by Leishmania major and Leishmania tropica: comparative findings and serology. Parasites Vectors. 2017;10:113.

26. Paşa S, Tetik Vardarlı A, Erol N, Karakuş M, Töz S, Atasoy A, et al. Detection of Leishmania major and Leishmania tropica in domestic cats in the Ege Region of Turkey. Vet Parasitol. 2015;212:389-92.

27. Can H, Döşkaya M, Özdemir HG, Şahar EA, Karakavuk M, Pektaş B, et al. Seroprevalence of Leishmania infection and molecular detection of Leishmania tropica and Leishmania infantum in stray cats of Izmir, Turkey. Exp Parasitol. 2016;167:109-14.

28. Maroli M, Feliciangeli MD, Bichaud L, Charrel RN, Gradoni L. Phlebotomine sandflies and the spreading of leishmaniases and other diseases of public health concern. Med Vet Entomol. 2012;27:123-47.

29. Svobodová M, Alten B, Zídková L, Dvorák V, Hlavacková J, Mysková J, et al. Cutaneous leishmaniasis caused by Leishmania infantum transmitted by Phlebotomus tobbi. Int J Parasitol. 2009;39:251-6.

30. Özbel Y, Karakuş M, Arserim SK, Kalkan ŞO, Töz S. Molecular detection and identification of Leishmania spp. in naturally infected Phlebotomus tobbi and Sergentomyia dentata in a focus of human and canine leishmaniasis in western Turkey. Acta Trop. 2016;155:89-94.

31. Maia C, Dionísio L, Afonso MO, Neto L, Cristóvão JM, Campino L. Leishmania infection and host-blood feeding preferences of phlebotomine sandflies and canine leishmaniasis in an endemic European area, the Algarve Region in Portugal. Mem Inst Oswaldo Cruz. 2013;108:481-7.

\section{Publisher's Note}

Springer Nature remains neutral with regard to jurisdictional claims in published maps and institutional affiliations. 